\title{
Metabolic network model guided engineering ethylmalonyl-CoA pathway to improve ascomycin production in Streptomyces hygroscopicus var. ascomyceticus
}

Junhua Wang ${ }^{1,2+}$, Cheng Wang ${ }^{1,2+}$, Kejing Song ${ }^{1,2}$ and Jianping Wen ${ }^{1,2^{*}}$

\begin{abstract}
Background: Ascomycin is a 23-membered polyketide macrolide with high immunosuppressant and antifungal activity. As the lower production in bio-fermentation, global metabolic analysis is required to further explore its biosynthetic network and determine the key limiting steps for rationally engineering. To achieve this goal, an engineering approach guided by a metabolic network model was implemented to better understand ascomycin biosynthesis and improve its production.
\end{abstract}

Results: The metabolic conservation of Streptomyces species was first investigated by comparing the metabolic enzymes of Streptomyces coelicolor A3(2) with those of 31 Streptomyces strains, the results showed that more than 72\% of the examined proteins had high sequence similarity with counterparts in every surveyed strain. And it was found that metabolic reactions are more highly conserved than the enzymes themselves because of its lower diversity of metabolic functions than that of genes. The main source of the observed metabolic differences was from the diversity of secondary metabolism. According to the high conservation of primary metabolic reactions in Streptomyces species, the metabolic network model of Streptomyces hygroscopicus var. ascomyceticus was constructed based on the latest reported metabolic model of S. coelicolor A3(2) and validated experimentally. By coupling with flux balance analysis and using minimization of metabolic adjustment algorithm, potential targets for ascomycin overproduction were predicted. Since several of the preferred targets were highly associated with ethylmalonyl-CoA biosynthesis, two target genes hcd (encoding 3-hydroxybutyryl-CoA dehydrogenase) and ccr (encoding crotonyl-CoA carboxylase/reductase) were selected for overexpression in S. hygroscopicus var. ascomyceticus FS35. Both the mutants HA-Hcd and HA-Ccr showed higher ascomycin titer, which was consistent with the model predictions. Furthermore, the combined effects of the two genes were evaluated and the strain $\mathrm{HA}-\mathrm{Hcd}-\mathrm{Ccr}$ with hcd and ccr overexpression exhibited the highest ascomycin production (up to $438.95 \mathrm{mg} / \mathrm{L}$ ), 1.43-folds improvement than that of the parent strain FS35 (305.56 mg/L).

Conclusions: The successful constructing and experimental validation of the metabolic model of S. hygroscopicus var. ascomyceticus showed that the general metabolic network model of Streptomyces species could be used to analyze the intracellular metabolism and predict the potential key limiting steps for target metabolites overproduction. The corresponding overexpression strains of the two identified genes ( $h c d$ and ccr) using the constructed model all

\footnotetext{
*Correspondence: jpwen@tju.edu.cn

† Junhua Wang and Cheng Wang contributed equally to this work

${ }^{2}$ SynBio Research Platform, Collaborative Innovation Center of Chemical

Science and Engineering (Tianjin), School of Chemical Engineering

and Technology, Tianjin University, Tianjin 300072, People's Republic

of China

Full list of author information is available at the end of the article
} 
displayed higher ascomycin titer. The strategy for yield improvement developed here could also be extended to the improvement of other secondary metabolites in Streptomyces species.

Keywords: Ascomycin, FK520, Metabolic network model, Ethylmalonyl-CoA pathway, Streptomyces hygroscopicus var. ascomyceticus

\section{Background}

Ascomycin (FK520) is a 23-membered polyketide macrolide antibiotic with immunosuppressant activity, which has similar characterization to FK506 (tacrolimus), exhibiting various therapeutic applications, including antifungal [1], immunosuppressive [2], antimalarial [3], antispasmodics [3] and several other uses [4, 5]. Meanwhile, many of its derivatives also have important pharmacological value, such as pimecrolimus, which has been confirmed to be effective in the treatment of various inflammatory skin diseases $[4,6]$. Due to its broad clinical applicability and promising pharmaceutical prospects, ascomycin and its derivatives have recently attracted much attention of many researchers.

Recently, considerable efforts have been made to enhance the ascomycin titer of the production strains, including random mutagenesis and selection [7], fermentation technology optimization [8], comparative metabolic profile analysis [9], and so on. However, the relatively low yield of ascomycin in bio-fermentations is still a major obstacle for its further industrialization and commercialization. This problem may be due to our poor understanding of the mechanism of ascomycin overproduction as well as a lack of methods to efficiently identify the key-limiting steps as targets for strain engineering. Recently, genome-scale metabolic network model (GSMM) [10] has been developed as an effective strategy to analyze the intracellular metabolic behavior and identify metabolic engineering targets for efficient strain improvement. It has been successfully applied to the design of metabolic engineering strategies for a number of valuable products, such as succinic acid [11], spinosad [12], tacrolimus [13], riboflavin [14], dicarboxylic acid [15], putrescine [16], and so on.

Streptomyces coelicolor A3(2), the model organism of the Streptomyces genus, is the first one to be completely sequenced species of the genus Streptomyces [17]. The GSMM of S. coelicolor A3(2) was first constructed in 2005 (iIB711) [18], and was updated in 2010 (iMA789) [19] and 2014 (iMK1208) [20]. During the construction of the model iIB711, the authors analyzed the universality of the model by comparing the genome of $S$. coelicolor A3(2) with that of Streptomyces avermitilis [18]. It was found that $78 \%$ ORFs in the model were synteny conserved with $S$. avermitilis and some of the non-conserved ORFs might have synteny-conserved isoenzymes with $S$. avermitilis. The results illustrated that metabolic genes were highly conservative in the above two Streptomyces strains. In addition, it has been demonstrated that the size of panmetabolism (the set of all reactions in the investigated strains) in Escherichia coli was limited to the set of reactions already known and approached a constant [21]. This phenomenon may be due to the conservation of metabolic genes in these organisms, as well as our limited knowledge of gene functions and protein biochemical characteristics [21, 22]. However, in Streptomyces species, the size of panmetabolism might not approach a plateau because they contain large number of genes in their secondary metabolism. Nevertheless, the primary metabolic genes in Streptomyces species are more conserved, which has been illustrated by comparing genome and pangenome analysis [23, 24]. Thus, one can expect that a newly sequenced Streptomyces strain would not significantly expand the size of the set of known primary metabolic reactions in Streptomyces species. That is, the construction of a general metabolic network model for Streptomyces strains only requires the addition of limited diversity to the current primary metabolic network of the model strain S. coelicolor A3(2).

Nevertheless, the metabolic conservation of Streptomyces species has so far not been fully analyzed, and the primary reactions in model iMK1208 of S. coelicolor A3(2) have not been investigated to establish if these reactions are conserved and could be applied to construct a general metabolic network model for Streptomyces strains. To resolve these issues, the metabolic enzymes in the updated model iMK1208 of S. coelicolor A3(2) were compared with those of 31 Streptomyces strains. And high conservation of the primary metabolic enzymes had been found in the all selected Streptomyces strains. Then, a metabolic network model of S. hygroscopicus var. ascomyceticus for ascomycin biosynthesis was attempted to construct by using the universal primary metabolic reactions from model iMK1208 and adding the reactions associated with the synthesis of ascomycin in S. hygroscopicus var. ascomyceticus. Using the thus constructed metabolic network model, some potential targets for ascomycin overproduction were predicted with the aid of FBA [25] and MOMA [26]. Among all the potential targets, two target genes (i.e. hcd and $c c r$ ) located in the ethylmalonyl-CoA pathway showed high promoting effects on ascomycin overproduction. After gene overexpression 
manipulation, all the engineered strains had shown higher ascomycin production than control, and the highest ascomycin titer reached to $438.95 \mathrm{mg} / \mathrm{L}$ in the strain HA-Hcd-Ccr. These findings not only suggested a general metabolic network model could be construed for Streptomyces species, but also provided an effective method for the titer improvement of other products in different Streptomyces species.

\section{Methods}

\section{Conservation analysis of the proteins in iMK1208 against Streptomyces species}

A total of 31 Streptomyces strains with completely sequenced genomes (deposited in the NCBI by September 2015) were used in the conservation analysis. All the available protein coding sequences of the 31 Streptomyces strains were retrieved from the National Center for Biotechnology Information (NCBI), and plasmids were omitted from the analysis. The accession numbers of all 31 strains are listed in Additional file 1. The protein sequences of $S$. coelicolor A3(2) in metabolic model iMK1208 were used as the reference, and the sequence similarities on protein level were calculated from a pairwise comparison of homologous sequences between the protein sequences in the model iMK1208 and the protein coding sequences of the 31 Streptomyces strains using BLAST v2.2.30+. The top hit for each protein sequence (i.e. lowest e value) was selected as the optimal comparison result. The protein sequences were considered as conserved at the threshold of $40 \%$ identity, $50 \%$ of query protein length aligned and e value $<1 \mathrm{e}-05$.

\section{Metabolic network construction}

The initial model of $S$. hygroscopicus var. ascomyceticus FS35 was constructed based on the model iMK1208 of $S$. coelicolor A3(2). Several secondary metabolism subsystems actinorhodin, undecylprodigiosin, calcium dependent antibiotic, and germicidin biosynthesis were removed from the model iMK1208. Some specific secondary metabolites biosynthesis reactions in other subsystems such as membrane transport, cofactor and prosthetic group biosynthesis were also removed from the model. The reactions related with ascomycin specific precursors biosynthesis and overall biosynthesis reactions were added to the new model.

As a kind of constraints-based metabolic model, the necessary constraints were used to obtain the optimal flux solution space. For example, 6-phosphogluconate dehydrogenase was shown to be NADP-dependent and no detectable activity with NAD [27], the upper bounds of reaction GND2 (NAD-dependent) and GND (NADPdependent) were set to 0 and 1000, respectively. Based on the way for glucose entry and phosphorylation, the upper bound of reaction G1DH was set to $0[27,28]$. According to the analysis of the carbon-flux distribution in S. coelicolor [27], S. hygroscopicus var. ascomyceticus [29] and S. lividans [30], the lower bound of reaction PGL (catalyzed by 6-phosphogluconolactonase) was set to 0.2 , which means that the lowest flux through pentose phosphate pathway was $20 \%$ of the available glucose- 6 -phosphate. Additionally, the lower bound of the anaplerotic reaction PPC was set to 0.1 according to the carbon-flux distribution of S. coelicolor [27]. Menaquinone biosynthesis pathway was also further improved according the Kyoto Encyclopedia of Genes and Genomes (KEGG) database. The details of the all reactions and metabolites in the models are provided in Additional file 2.

\section{Identification of the overexpression targets}

Flux balance analysis (FBA) was performed to calculate the flux distributions throughout the metabolic network by defining a maximized-biomass equation as the objective function using COBRAToolbox-2.0 [31] in MATLAB [32-35]. To further validate the model, the predicted specific growth rates in a glucose-limited minimal medium were compared with the observed growth in glucose limited environments [36]. The algorithm developed by Boghigian et al. was applied for the identification of overexpression targets [37]. First, FBA was used to calculate the initial flux distribution for the network by defining the maximized specific growth rate as the objective function. Subsequently, each non-zero reaction flux obtained by FBA was amplified to some extent, and MOMA was performed to search for the minimal Euclidean distance between the original model and the model after gene perturbation by solving a quadratic programming problem. The overexpression targets were identified by comparing the $f_{\mathrm{PH}}$ value (Eq. 1), defined as the ratio of the weighted and dimensionless specific growth rate and the specific ascomycin production rate. Overexpression targets with higher $f_{\mathrm{PH}}$ values were regarded as better candidates for experimental manipulation.

$$
\begin{aligned}
f_{\mathrm{PH}} & =\left(f_{\text {biomass }}\right) \times\left(f_{\text {ascomycin }}\right) \\
& =\left(\frac{\nu_{\text {biomass,overexpression }}}{v_{\text {biomass,wild }}}\right)\left(\frac{v_{\text {ascomycin,overexpression }}}{v_{\text {ascomycin,wild }}}\right)
\end{aligned}
$$

Bacterial strains, plasmids, and cultural conditions

All strains and plasmids used in this study are summarized in Table 1 . The parent strain $S$. hygroscopicus var. ascomyceticus FS35 was isolated after femtosecond laser irradiation [7]. All S. hygroscopicus var. ascomyceticus mutants used in this study were derived from FS35. Escherichia coli JM109 was used to propagate all plasmids. E. coli ET12567/pUZ8002 was used as the 
Table 1 Bacterial strains and plasmids used in this study

\begin{tabular}{|c|c|c|}
\hline Strains/plasmids & Relevant features & Source/reference \\
\hline \multicolumn{3}{|l|}{ Strains } \\
\hline S. hygroscopicus var. ascomyceticus FS35 & Mutant, improved ascomycin producer & {$[7]$} \\
\hline FS-PIB & FS35 transformed with plB139 & This study \\
\hline $\mathrm{HA}-\mathrm{Ccr}$ & FS35 transformed with plB/ccr & This study \\
\hline $\mathrm{HA}-\mathrm{Hcd}$ & FS35 transformed with plB/hcd & This study \\
\hline $\mathrm{HA}-\mathrm{Hcd}-\mathrm{Ccr}$ & FS35 transformed with plB/hcd/ccr & This study \\
\hline E. coli DH5a & Plasmid construction and general cloning & Takara \\
\hline E. coli ET12567 & pUZ8002, nonmethylating plasmid donor, $\mathrm{Cm}^{\mathrm{R}}, \mathrm{Kan}^{\mathrm{R}}$ & [40] \\
\hline \multicolumn{3}{|l|}{ Plasmids } \\
\hline pUC18 & E. coli general cloning vector, $\mathrm{Amp}^{\mathrm{R}}$ & [41] \\
\hline plB139 & $\begin{array}{l}\text { Integrative E. coli-Streptomyces shuttle plasmid containing oriT, attP, int, aac(3)IV and } \\
\text { ermEp* }\end{array}$ & [42] \\
\hline $\mathrm{plB} / \mathrm{ccr}$ & plB139 based integrative plasmid containing ccr gene, $\mathrm{Apr}^{\mathrm{R}}$ & This study \\
\hline $\mathrm{plB} / \mathrm{hcd}$ & plB139 based integrative plasmid containing hcd gene, $\mathrm{Apr}^{\mathrm{R}}$ & This study \\
\hline $\mathrm{pUC/hcd}$ & pUC18 based plasmid containing hcd gene & This study \\
\hline $\mathrm{pUC/hcd/ccr}$ & pUC18 based plasmid containing hcd and ccr gene & This study \\
\hline $\mathrm{plB} / \mathrm{hcd} / \mathrm{ccr}$ & plB139 based integrative plasmid containing hcd-ccr gene, $\mathrm{Apr}^{\mathrm{R}}$ & This study \\
\hline
\end{tabular}

nonmethylating plasmid donor strain for intergeneric conjugation with FS35. All E. coli strains were grown in Luria-Bertani (LB) medium at $37^{\circ} \mathrm{C}$. The integrative $E$. coli-Streptomyces shuttle vector pIB139 containing the ermE* promoter $\left(P_{\text {ermE* }}\right)$ was used for gene overexpression in S. hygroscopicus var. ascomyceticus FS35. S. hygroscopicus var. ascomyceticus strains was grown at $\mathrm{pH} 7.0$ and $28{ }^{\circ} \mathrm{C}$, MS medium was used for the preparation of Streptomyces spores suspensions, seed cultures were prepared as described previously [38]. Synthetic medium was used to culture the FS35 strain for model validation, and it contained $40 \mathrm{~g} / \mathrm{L}$ dextrin, $20 \mathrm{~g} / \mathrm{L}$ glucose, $1.0 \mathrm{~g} / \mathrm{L}$ $\mathrm{NaCl}, 2.0 \mathrm{~g} / \mathrm{L}(\mathrm{NH} 4)_{2} \mathrm{SO}_{4}, 1.0 \mathrm{~g} / \mathrm{L} \mathrm{K}_{2} \mathrm{HPO}_{4} \cdot 3 \mathrm{H}_{2} \mathrm{O}, 2.0 \mathrm{~g} / \mathrm{L}$ $\mathrm{CaCO}_{3}, 1.0 \mathrm{~g} / \mathrm{L} \mathrm{MgSO} \cdot 7 \mathrm{H}_{2} \mathrm{O}, 0.001 \mathrm{~g} / \mathrm{L} \mathrm{FeSO} \cdot 7 \mathrm{H}_{2} \mathrm{O}$, $0.001 \mathrm{~g} / \mathrm{L} \mathrm{MnCl}_{2} \cdot 4 \mathrm{H}_{2} \mathrm{O}, 0.001 \mathrm{~g} / \mathrm{L} \mathrm{ZnSO}_{4} \cdot 7 \mathrm{H}_{2} \mathrm{O}, \mathrm{MOPS}$ $5.0 \mathrm{~g} / \mathrm{L}, \mathrm{pH}$ 7.0. The production medium contained $20 \mathrm{~g} / \mathrm{L}$ soluble starch, $40 \mathrm{~g} / \mathrm{L}$ dextrin, $5.0 \mathrm{~g} / \mathrm{L}$ peptone, $5.0 \mathrm{~g} / \mathrm{L}$ yeast powder, $6.0 \mathrm{~g} / \mathrm{L}$ corn steep liquor, $12 \mathrm{~mL} / \mathrm{L}$ soybean oil, $1.0 \mathrm{~g} / \mathrm{L} \mathrm{MgSO}{ }_{4} \cdot 7 \mathrm{H}_{2} \mathrm{O}, 0.5 \mathrm{~g} / \mathrm{L} \mathrm{MnSO}_{4} \cdot 1 \mathrm{H}_{2} \mathrm{O}$, $1.5 \mathrm{~g} / \mathrm{L}(\mathrm{NH} 4)_{2} \mathrm{SO}_{4}, 0.5 \mathrm{~g} / \mathrm{L} \mathrm{K}_{2} \mathrm{HPO}_{4} \cdot 3 \mathrm{H}_{2} \mathrm{O}$, and $2.0 \mathrm{~g} / \mathrm{L}$ $\mathrm{CaCO}_{3}$. Streptomyces coelicolor A3(2) were cultured in YEME at $28{ }^{\circ} \mathrm{C}$ for the isolation of genome. For conjugation experiments, S. hygroscopicus var. ascomyceticus strains were performed according to the Streptomyces standard protocols [39]. The transformants of S. hygroscopicus var. ascomyceticus were selected on 2CMY contained starch $10 \mathrm{~g} / \mathrm{L}$, casein tryptone $2.0 \mathrm{~g} / \mathrm{L}, \mathrm{NaCl}$ $1.0 \mathrm{~g} / \mathrm{L},\left(\mathrm{NH}_{4}\right)_{2} \mathrm{SO}_{4} 2.0 \mathrm{~g} / \mathrm{L}, \mathrm{K}_{2} \mathrm{HPO}_{4} 1.0 \mathrm{~g} / \mathrm{L}, \mathrm{CaCO}_{3}$ $2.0 \mathrm{~g} / \mathrm{L}, \mathrm{FeSO}_{4} \cdot 7 \mathrm{H}_{2} \mathrm{O} 0.001 \mathrm{~g} / \mathrm{L}, \mathrm{MgCl}_{2} \cdot 6 \mathrm{H}_{2} \mathrm{O} 0.001 \mathrm{~g} / \mathrm{L}$, $\mathrm{ZnSO}_{4} \cdot 7 \mathrm{H}_{2} \mathrm{O} 0.001 \mathrm{~g} / \mathrm{L}$, agar $20 \mathrm{~g} / \mathrm{L}, \mathrm{pH}$ 7.0. Agar plates by overlaying with an appropriate antibiotic or combination of antibiotics.

\section{Cloning, plasmid construction and transformation}

General DNA manipulation and intergeneric conjugation of $E$. coli with Streptomyces were performed according to standard protocols [39]. All the strains and primers used in this work are listed in Additional file 3: Table S1. A derivative of pSET152 [43], pIB139, was used for hcd and ccr gene overexpression. The plasmids $\mathrm{pIB} / \mathrm{ccr}$ and $\mathrm{pIB} /$ hcd were constructed as follows. The coding sequence of $h c d$ and $c c r$ were amplified from the genomic DNA of S. coelicolor A3(2) by PCR using the primer pairs hcdF1/ hcdR1 and ccrF1/ccrR1 respectively. The hcd and $c c r$ PCR products were digested using the restriction enzymes $N d e \mathrm{I}$ and $\mathrm{Xba \textrm {I }}$, and the resulting fragments produced by digestion were cloned into the pIB139 vector between NdeI and XbaI respectively to obtain pIB139R and pIB139D, respectively. The constructed plasmids pIB/ hcd and pIB/ccr were both confirmed by DNA sequencing. The conformed plasmids pIB/hcd and $\mathrm{pIB} / \mathrm{ccr}$ were introduced into the parent strain S. hygroscopicus var. ascomyceticus FS35 to obtain the hcd and ccr overexpression strains HA-Hcd and HA-Ccr, respectively. To construct the vector $\mathrm{pIB} / \mathrm{hcd} / \mathrm{ccr}$, the primer pairs HcdF2 and HcdR2 were used for amplifying the gene hcd and the primer pairs CcrF2 and CcrR2 were used for amplifying the gene $c c r$. The hcd PCR product was digested using NdeI and Pst I, and then the fragment was cloned into the pUC18 vector to form $\mathrm{pUC} / \mathrm{hcd}$. The resulted plasmid 
pUC/hcd was cut using PstI and XbaI, and linked with the $c c r$ PCR product, which was digested with the same restriction enzymes, to form the plasmid $\mathrm{pUC} / \mathrm{hcd} / \mathrm{ccr}$. The plasmid pUC/ccr/hcd was excised by NdeI/XbaI and the fragment including gene $h c d$ and $c c r$ was cloned into pIB139 to generate the plasmid $\mathrm{pIB} / \mathrm{hcd} / \mathrm{ccr}$. The resulting plasmid was introduced into the parental strain $S$. hygroscopicus var. ascomyceticus FS35 via conjugal transfer, generating the overexpression strain HA-Hcd-Ccr. The parental strain S. hygroscopicus var. ascomyceticus FS35 with pIB139 (FS-PIB) was used as the negative control. All the positive mutants were confirmed by PCR amplification and DNA sequence analysis.

\section{Enzyme assays}

The culture samples for enzyme activity analysis in vitro were harvested at the end of exponential phase $(72 \mathrm{~h})$ by centrifugation at $8000 \times g$ for $10 \mathrm{~min}$ at $4{ }^{\circ} \mathrm{C}$. Cell pellets were washed 3 times by $100 \mathrm{mM}$ Tris. $\mathrm{HCl}(\mathrm{pH}$ 7.0) containing $5 \mathrm{mM} \mathrm{MnSO}_{4}, 20 \mathrm{mM} \mathrm{KCl}, 2 \mathrm{mM}$ DTT and $0.1 \mathrm{mM}$ EDTA, and then resuspended in the same buffer [44]. Cell suspension was treated by ultrasonication for $10 \mathrm{~min}$ at $250 \mathrm{~W}$ for 5 cycles of $1 \mathrm{~min}$ each on ice bath. Supernatant obtained after centrifugation at $12,000 \times g$ for 20 min at $4{ }^{\circ} \mathrm{C}$ was stored at $-80{ }^{\circ} \mathrm{C}$ for assays of enzyme activity and total protein concentration. The concentration of total protein was detected by the Bradford method [45]. One unit (1 U) of enzyme activity was defined as the transformation of $1 \mu \mathrm{M} / \mathrm{min}$.

3-Hydroxybutyryl-CoA dehydrogenase (Hcd, EC:1.1.1.157) activity was assayed by monitoring the decrease in NADH concentration at $340 \mathrm{~nm}$ using acetoacetyl-CoA as the substrate, the reaction mixture contained $100 \mathrm{mM}$ Tris-HCl buffer (pH 7.5), $100 \mu \mathrm{M}$ acetoacetyl-CoA, $150 \mu \mathrm{M} \mathrm{NADH}$, and extract. The reaction was started by the addition of acetoacetyl-CoA [46, 47]. Activity of the crotonyl-CoA carboxylase/reductase (Ccr, EC:1.3.1.85) was assayed by the method reported previously [48].

\section{Analytical methods}

Fermentations of S. hygroscopicus var. ascomyceticus FS35 and its derivatives were carried out as described previously [38]. Biomass concentration was determined by the measurement of dry cell weight (DCW). For the determination, $10 \mathrm{~mL}$ fermentation broth were sampled and then centrifuged at $8000 \times g$ for $10 \mathrm{~min}$, washed once with $0.1 \mathrm{M} \mathrm{HCl}$ and twice with distilled water separately, and dried at $80{ }^{\circ} \mathrm{C}$ to constant weight. The concentration of ascomycin was quantitated by high-performance liquid chromatography (HPLC) analysis as described previously [38]. The residual total sugar in fermentation broth was quantified according to the phenol-sulfuric acid method using glucose as the standard [49].

\section{Results \\ Metabolic conservation analysis in Streptomyces species}

All the metabolic enzymes involved in the iMK1208 model of S. coelicolor A3(2), which is an important model strain for Streptomyces species, were used as the standard for metabolic conservation analysis of 31 Streptomyces strains. Except for the exchange and teichoic acid biosynthesis subsystems, the 1208 proteins in the other 43 metabolic subsystems of the model iMK1208 were preformed blastp homology analysis against 31 Streptomyces strains (Additional file 1). The names of these strains were constituted by the strain numbers in this study and the KEGG numbers except the strain S. hygroscopicus limoneus KCTC 1717. As shown in Fig. 1, 1208 metabolic enzymes involved in the model were highly conserved among the 31 Streptomyces strains. The strain S17-slv had highest homology (98\%) and the stain S31-sxi had lowest homology (72\%) with the all 1208 metabolic enzymes. Specially, 24 strains had higher homology more than $80 \%$, and only 2 strains had homology least than $75 \%$ with the analyzed proteins in S. coelicolor A3(2). The conservation of metabolic enzymes from different metabolic subsystems in Streptomyces species was also investigated by cluster analysis. The conservation of different subsystems showed a similar distribution in all strains (Additional file 3: Figure S1). Interestingly, the metabolic diversity mainly stemmed from the subsystems related to secondary metabolism, including actinorhodin biosynthesis (01-ActB), calcium-dependent antibiotics biosynthesis (08-CDAB), germicidin biosynthesis (16-GerB) and undecylprodigiosin biosynthesis (42-UndB).

In addition to the above significant differences in secondary metabolism, further concrete analysis of proteins within the primary metabolism was conducted using $S$. hygroscopicus jinggangensis 5008 (S14-shy) and S. hygroscopicus limoneus KCTC 1717 (S16-shyl) as examples. Homology analysis of 1166 primary metabolic enzymes from S. coelicolor A3(2) was preformed against S14shy and S16-shyl. Both strains showed high numbers of enzymes homologous with those of the primary metabolic enzymes in S. coelicolor A3(2) (Fig. 2a and Additional file 3: Figure S2). In fact, only 146 and 169 proteins had no homologs in S14-shy and S16-shyl, respectively. It was also discovered that some of the non-homologous proteins might have homologous isoenzymes in the two strains. As for the strain S14-shy (Fig. 2a), it did not share significant sequence similarity with 146 proteins related to the primary metabolism of S. coelicolor A3(2). However, among these 146 proteins, there were 95 proteins 


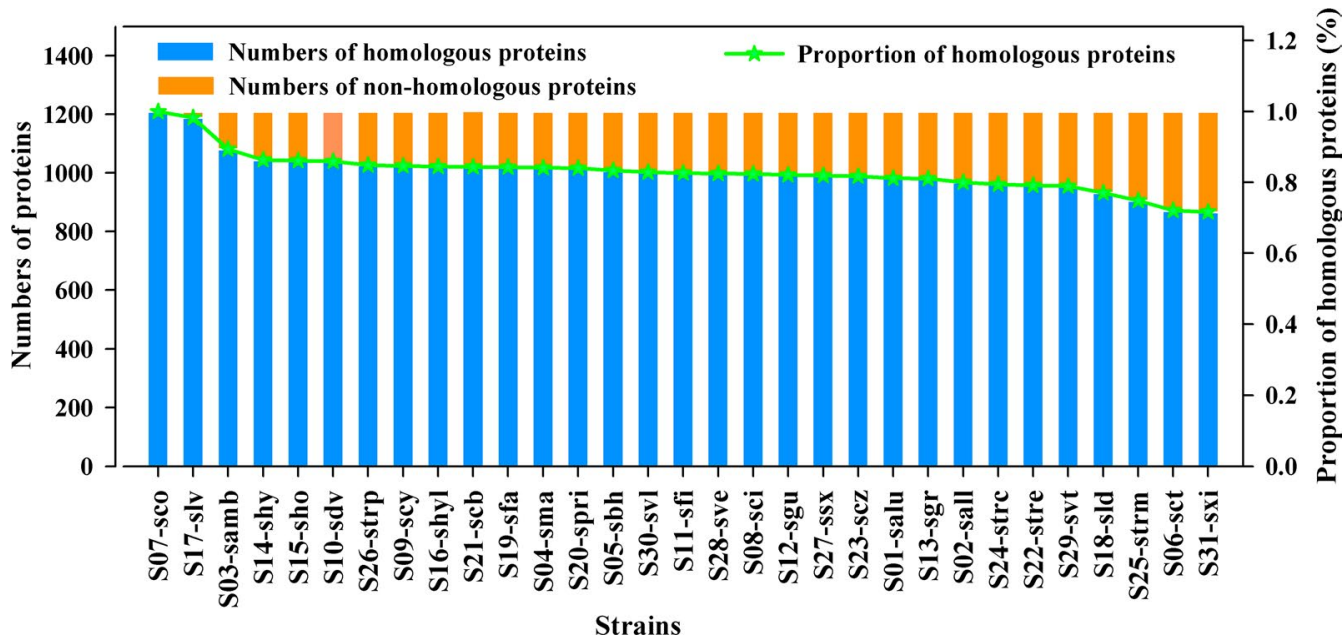

Fig. 1 Conservation analysis of metabolic enzymes between Streptomyces coelicolor A3(2) and 31 Streptomyces strains. The proteins in the metabolic model iMK1208 of S. coelicolor A3(2) were used as a reference for protein conservation analysis of the 31 Streptomyces strains. The strains are indicated by the strain numbers in this study and their KEGG organism codes except for the strain S. hygroscopicus limoneus KCTC 1717, which is indicated by S16-shyl. S07-sco is short for S. coelicolor A3(2), which is the reference strain for conservation analysis

with at least one isozyme present in S14-shy. Moreover, among the remaining 51 non-homologous proteins, 15 had similar protein annotation information with proteins in S14-shy. Taking all these factors into consideration, there were only 36 proteins without homologs among all 1166 primary metabolic related proteins from S14-shy, which represents a mere $3 \%$ of all proteins in the primary metabolism subsystems of the metabolic network model of S. coelicolor A3(2). Similar results were also obtained for the strain S16-shyl (Additional file 3: Figure S2). Moreover, the non-homologous proteins were mainly distributed in the subsystems related to environmental adaptability, such as alternate carbon metabolism (03-ACM), inorganic ion transport (23-IITM), nitrogen metabolism (29-NitM) and membrane transport (38TraM) (Fig. 2b). Thus, there were only minor differences in the primary metabolism of the analyzed Streptomyces species.

\section{Metabolic network reconstruction and in silico identification of potential targets}

According to the previous described methods (seen in the "Methods" section: Metabolic network construction), the metabolic network model of S. hygroscopicus var. ascomyceticus FS35 was constructed based on the model of S. coelicolor A3(2), and the details are listed in the Additional file 2. Using the maximum growth rate as an objective function, the constructed model was verified by comparing the specific growth rate from the simulation with experimental data. In the model simulation, the specific glucose uptake rate was set to $0.90 \mathrm{mM} / \mathrm{g}$
$\mathrm{DCW} / \mathrm{h}$ and the specific ascomycin synthetic rate was set to $5 \times 10^{-4} \mathrm{mM} / \mathrm{g}$ DCW/h respectively. Based on the above constraints, the maximal specific growth rate calculated by the model was $0.0653 / \mathrm{h}$, which was very close to the experimental result of $0.0616 / \mathrm{h}$ (Additional file 3 : Figure S3).

After model verification, the potential overexpression targets for ascomycin overproduction were predicted by coupling the model with FBA and MOMA algorithms. In order to improve the accuracy, targets located in the inorganic ion transport and metabolism, exchange and nucleotide salvage pathway subsystems were excluded in advance. The targets related to ATP maintenance requirements were also been excluded. Using their respective $f_{\mathrm{PH}}$ values [37], 29 potential gene overexpression targets were identified, including 22 from the primary metabolism and 7 from the secondary metabolism (Fig. 3). The details of all predicted targets are listed in Additional file 2. Among these, the targets HACD1, ECOAH1 and ACACT1r had the highest $f_{\mathrm{PH}}$ at 6.059. The corresponding reactions are catalyzed by 3-hydroxybutyryl-CoA dehydrogenase, 3-hydroxybutyryl-CoA dehydratase and acetyl-CoA C-acetyltransferase, respectively. All the three targets are involved in the transformation of acylCoA into crotonyl-CoA, and the latter is an important precursor for the supply of ethylmalonyl-CoA [48, 50]. The target TALA was catalyzed by transaldolase, which converts glyceraldehyde 3-phosphate and sedoheptulose 7-phosphate into D-erythrose 4-phosphate (E4P) and D-fructose 6-phosphate. In transaldolase-overexpressing strain, the carbon flux to E4P was enhanced which 


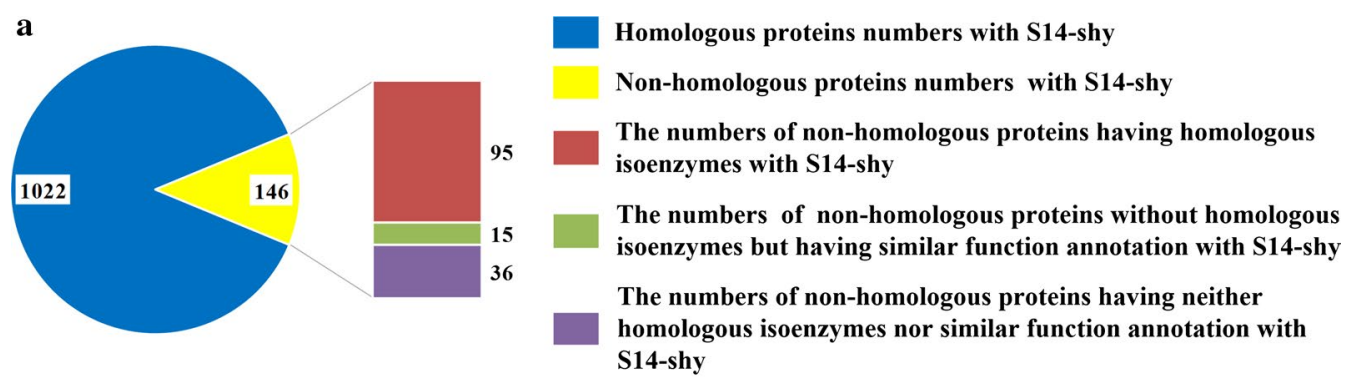

b

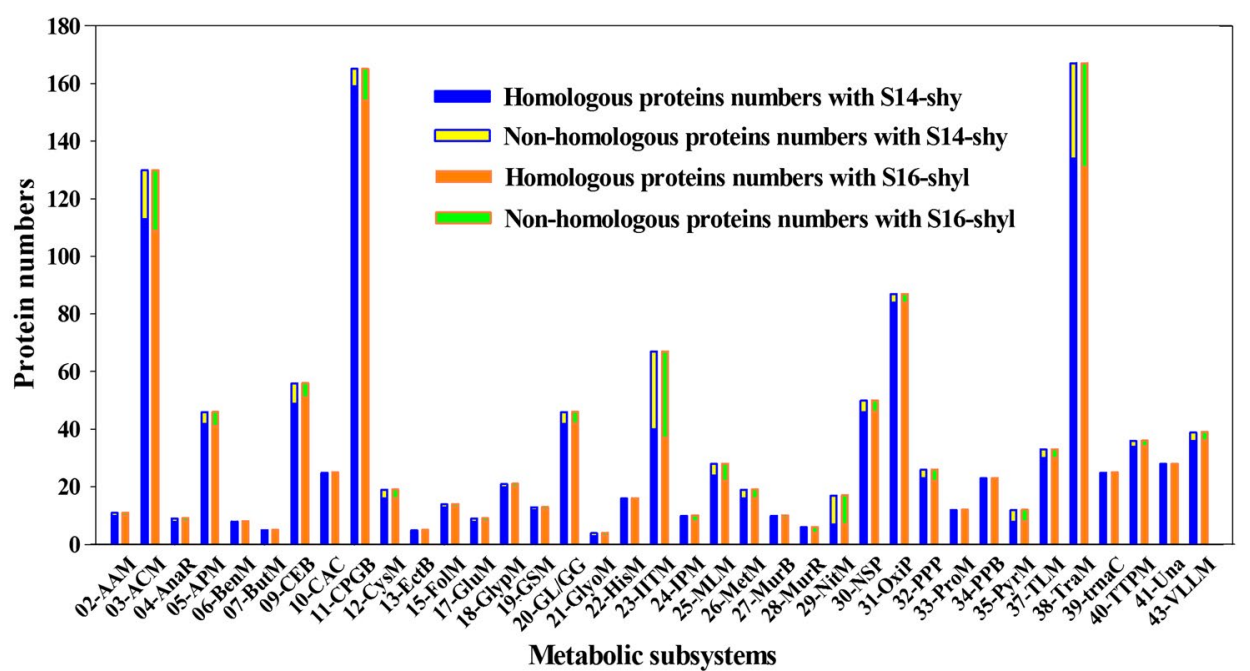

Fig. 2 Conservation analysis of primary metabolic enzymes of S. coelicolor A3(2) compared with two S. hygroscopicus strains. The proteins involved in the primary metabolic subsystems of the metabolic model iMK1208 of S. coelicolor A3(2) were used as reference for protein conservation analysis of S. hygroscopicus jinggangensis 5008 (S14-shy) and S. hygroscopicus limoneus KCTC 1717 (S16-shyl). a Homology analysis of proteins related to primary metabolism in S. coelicolor A3(2) and S14-shy. The distribution of homologous and non-homologous proteins in the primary metabolic subsystems of the model iMK1208 against S14-shy is shown in the pie chart. The details of the numbers of non-homologous proteins owing isoenzymes or similar function annotation with the strain S14-shy are also listed in the bar of the pie chart. b Comparison of the proteins in different primary metabolic subsystems of the model iMK1208 with those from the strains S14-shy and S16-shyl respectively. Four secondary metabolism subsystems and two primary metabolism subsystems (not including any proteins in model) were not included in this analysis

resulted in an increased supply of shikimate acid [38]. The targets MOHMT, PANTS, PNTK, PPNCL2, DPR and PPCDC are involved in the synthesis of pantetheine 4'-phosphate (an intermediate in coenzyme A biosynthesis pathway), which is an essential prosthetic group of acyl carrier protein (ACP), and a key cofactor in the biosynthesis of polyketides and fatty acids [51-53]. The next target, CCCR $\left(f_{\mathrm{PH}}=1.906\right)$ was catalyzed by crotonylCoA carboxylase/reductase (Ccr). In this reaction, crotonyl-CoA could be transformed into ethylmalonyl-CoA, an important precursor in ascomycin biosynthesis [54]. Overexpressing the two targets MME and MMM, catalyzed by methylmalonyl-CoA epimerase and methylmalonyl-CoA mutase respectively, would also increase the precursor level of ascomycin biosynthesis. Additionally, the secondary metabolic reactions FK1, FK2, FK3, FK4, FK5, FK6 and FK7 were also predicted as overexpression targets, suggesting that engineering secondary metabolic pathways might improve the production of ascomycin. In fact, this strategy had been proven effective in promoting the production of many secondary metabolites production [55-58].

\section{Improving ascomycin production by engineering the ethylmalonyl-CoA pathway}

According to the prediction results, it was found that several of the promising targets were highly associated with ethylmalonyl-CoA biosynthesis or directly located in the ethylmalonyl-CoA pathway. Consequently, two targets (HACD1 and CCCR) involved in the ethylmalonyl-CoA pathway were selected for the experimental overexpression. HACD1 and CCCR were catalyzed by 3-hydroxybutyryl-CoA dehydrogenase (Hcd) and crotonyl-CoA carboxylase/reductase (Ccr), respectively (Additional 


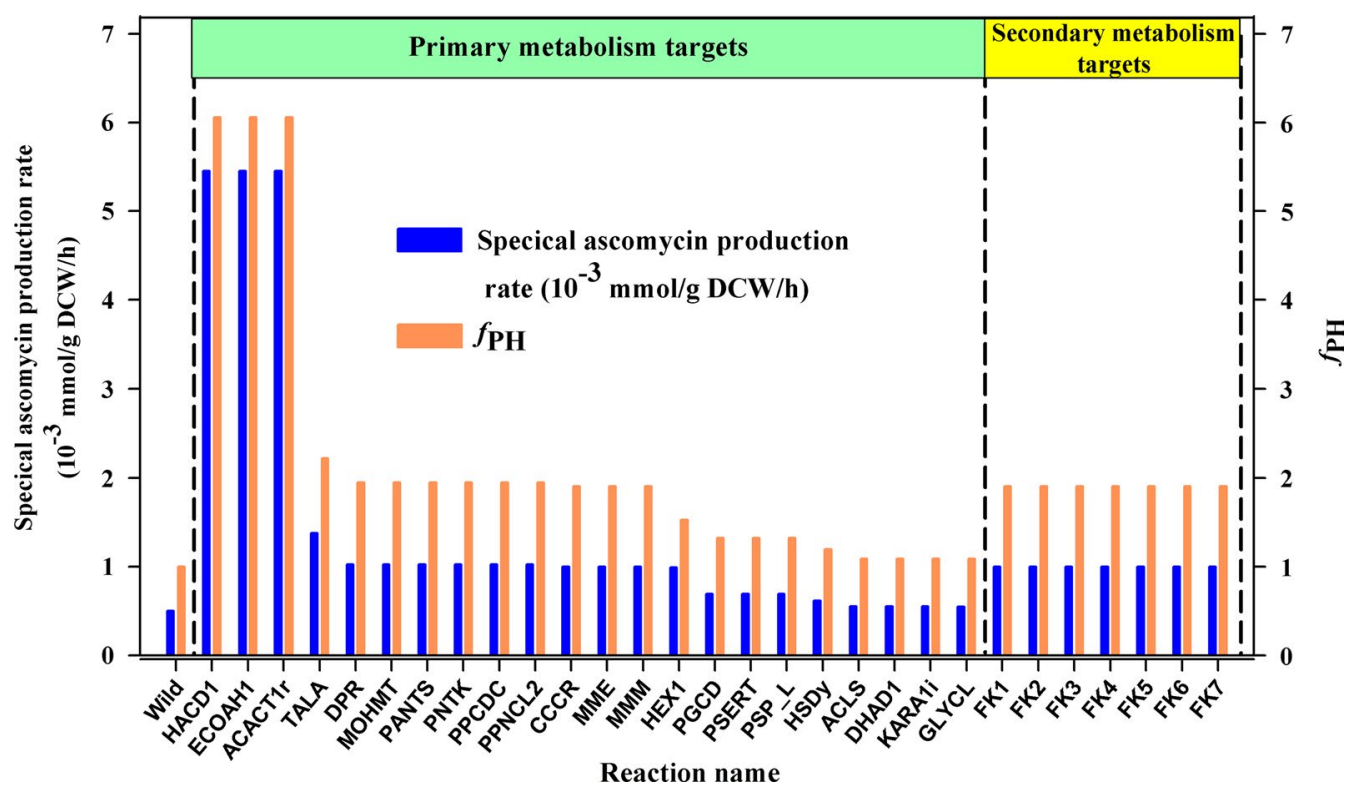

Fig. 3 Predicted effects of single reaction perturbation on the specific ascomycin production and $f_{\mathrm{PH}}$ values

file 3: Table S2). To verify the accuracy of the model prediction, the $h c d$ and $c c r$ genes were individually overexpressed and co-overexpressed in S. hygroscopicus var. ascomyceticus respectively (Table 2 ). In the $h c d$-overexpressing strain HA-Hcd, the 3-hydroxybutyryl-CoA dehydrogenase activity was $0.49 \mathrm{U} / \mathrm{mg}$ protein, representing a 1.96-fold increase over the parent strain FS35 (0.25 U/mg protein). In the ccr-overexpressing strain HA-Ccr, the crotonyl-CoA carboxylase/reductase activity was $0.28 \mathrm{U} / \mathrm{mg}$ protein, an increase of 2.5 times over the control $(0.08 \mathrm{U} / \mathrm{mg}$ protein). The enzymes activity in each mutant strain was higher than parental strain, which confirmed that both hcd and $c c r$ genes were overexpressed. In addition, in the strain HA-Ccr, the 3-hydroxybutyrylCoA dehydrogenase activity was $0.27 \mathrm{U} / \mathrm{mg}$ protein, a similar level with that of the control $(0.25 \mathrm{U} / \mathrm{mg}$ protein). By contrast, in the $h c d$-overexpressed strain HA-Hcd, the crotonyl-CoA carboxylase/reductase activity was 0.13

Table 2 Specific activity of enzymes by parent strain $S$. hygroscopicus var. ascomyceticus FS35 and recombinants in batch cultures

\begin{tabular}{lll}
\hline Strains & \multicolumn{2}{l}{ Enzyme activites (U/mg protein) } \\
\cline { 2 - 3 } & Hcd & Ccr \\
\hline FS35 & $0.25 \pm 0.03$ & $0.08 \pm 0.01$ \\
HA-Hcd & $0.49 \pm 0.05$ & $0.13 \pm 0.01$ \\
HA-Ccr & $0.27 \pm 0.03$ & $0.28 \pm 0.03$ \\
HA-Hcd-Ccr & $0.55 \pm 0.05$ & $0.35 \pm 0.04$ \\
\hline
\end{tabular}

$\mathrm{U} / \mathrm{mg}$ protein, which was 1.62 -fold higher than that of the control $(0.08 \mathrm{U} / \mathrm{mg}$ protein). In the strain HA-Hcd, the ascomycin production reached up to $375.32 \mathrm{mg} / \mathrm{L}$ at $168 \mathrm{~h}$, increased 1.23 times compared with that of the parent strain FS35 (305.56 mg/L) (Fig. 4). And in the strain HA-Ccr, the ascomycin production reached $361.67 \mathrm{mg} / \mathrm{L}$ at $168 \mathrm{~h}$, representing 1.18-fold increase over the parent strain FS35 (Fig. 4). Importantly, there were no obvious changes in biomass concentration between the engineered strains HA-Hcd and HA-Ccr, and the parent strain FS35. Finally, the combined overexpression of $h c d$ and $c c r$ was also investigated. Similar

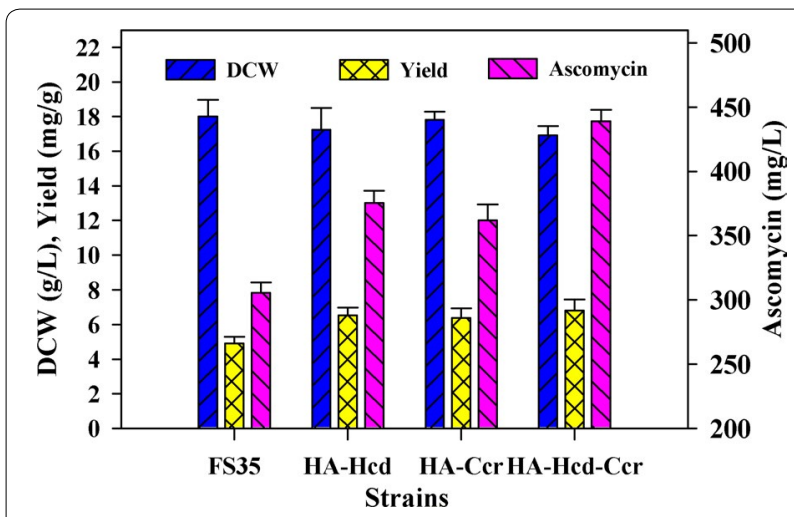

Fig. 4 Experimental effects of target gene manipulation on ascomycin production and cell growth. The data represent the average values of at least three independent experiments and the error bars represent the standard deviations 
with the overexpression of single gene, the growth of the double-overexpression strain HA-Hcd-Ccr was not significantly influenced. Its 3-hydroxybutyryl-CoA dehydrogenase activity was $0.55 \mathrm{U} / \mathrm{mg}$ protein, 1.2 -fold higher than that of the control $(0.25 \mathrm{U} / \mathrm{mg}$ protein). The crotonyl-CoA carboxylase/reductase activity was $0.35 \mathrm{U} /$ mg protein, and thus was increased 3.37 times compared with that of the parent strain FS35 (0.08 U/mg protein). Enzyme activity analysis confirmed that the activity of 3-hydroxybutyryl-CoA dehydrogenase and crotonyl-CoA carboxylase/reductase activity in the strain HA-HcdCcr was significantly improved compared with the control strain FS35. The final biomass concentration of the double-overexpression strain $(16.92 \mathrm{~g} / \mathrm{L}$ at $168 \mathrm{~h})$ exhibited a slightly decrease compared with the parent strain FS35 (18.02 g/L at $168 \mathrm{~h}$ ) (Fig. 5). Nevertheless, the final ascomycin production was obviously improved, reaching $438.95 \mathrm{mg} / \mathrm{L}$ at $168 \mathrm{~h}$, which was a 1.43 -fold increase over that of the parent strain FS35 $(305.56 \mathrm{mg} / \mathrm{L})$. The yield of ascomycin in HA-Hcd-Ccr was enhanced to $6.80 \mathrm{mg} / \mathrm{g}$ glucose from $4.91 \mathrm{mg} / \mathrm{g}$ glucose, and was thus 1.38-fold higher than that of the parent strain FS35.

\section{Discussion}

In previous reports, GSMM was confirmed as an effective method for better understanding of intracellular metabolic behavior and identifying the key limiting steps for target metabolites biosynthesis. In Streptomyces species, the GSMM of S. coelicolor A3(2) has been constructed and updated for 2 times and successfully used in the guide of metabolic engineering targets identity [18-20]. It has also been used as a model for guiding the constructing other metabolic network models for some Streptomyces species [13, 59]. However, though several GSMM had been constructed in some Streptomyces species, the conservation of these metabolic reactions existed in the reported GSMM had not been investigated completely. Previous studies showed that primary metabolism might be highly conserved between Streptomyces species [23, 24]. To investigate whether the primary metabolic reactions in the metabolic network model of $S$. coelicolor A3(2) are conserved in other Streptomyces species, a more comprehensive, deeper metabolic gene analysis of Streptomyces species was performed in this study.

The metabolic conservation of Streptomyces species was investigated by comparing the metabolic enzymes in the latest reported model of S. coelicolor A3(2) with those of 31 completely sequenced Streptomyces strains. The results showed that the metabolic enzymes were highly conserved within the 31 Streptomyces strains, especially for primary metabolism. This was consistent with the previous comparative genome and pangenome analyses of Streptomyces species [18, 23, 24]. Furthermore, only minor differences were founded in the primary metabolism of Streptomyces species, and metabolic reactions showed higher conservation than the data obtained through protein homology analysis. Therefore, majority of the primary metabolic reactions in the model of $S$. coelicolor A3(2) are likely universal across Streptomyces species. In addition, due to the conservation of metabolic

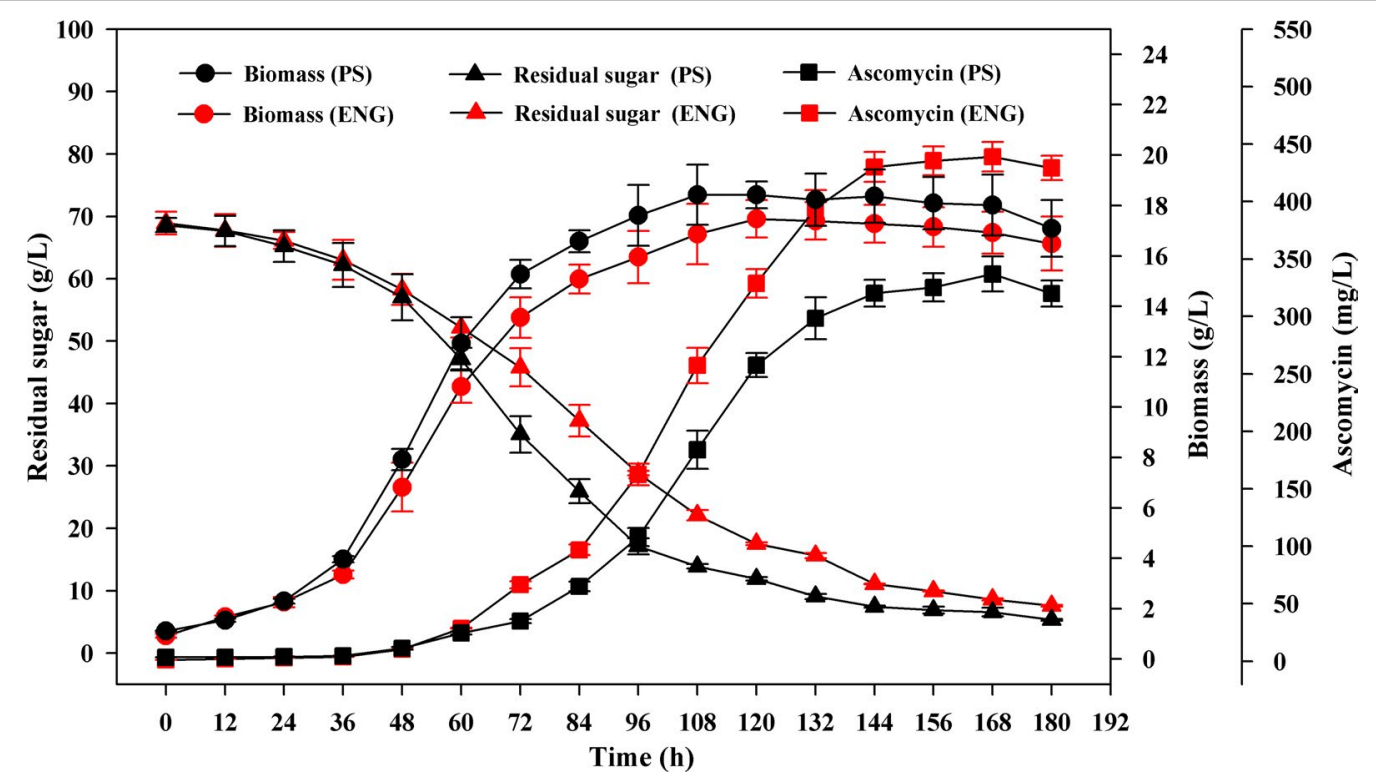

Fig. 5 The fermentation kinetics of the parent strain S. hygroscopicus var. ascomyceticus FS35 and its derived engineered stain $\mathrm{HA}-\mathrm{Hcd}-\mathrm{Ccr}$ under the same culture conditions. PS indicates the parent strain FS35, and ENG indicates the engineered strain HA-Hcd-Ccr. The data represent the means of at least three series of three parallel tests, and the error bars represent standard deviations 
genes and our limited knowledge of gene functions and biochemical characteristics, the set of primary metabolic reactions in Streptomyces strains is expected to converge to a constant value with the addition of analyzed genomes, as was demonstrated for $E$. coli strains $[21,22]$. Considering the universal nature of reactions in the primary metabolism and the fact that strain-specific portions of the primary metabolism remain largely uncharacterized in Streptomyces species, it is reasonable to reference the primary metabolic reactions in the model of S. coelicolor A3(2) to construct general metabolic network models for other Streptomyces strains.

As an important application of the general metabolic model, the GSMM of S. hygroscopicus var. ascomyceticus was firstly attempted to be constructed and applied to identify the genetic engineering targets for improving ascomycin production. The constructed metabolic model of S. hygroscopicus var. ascomyceticus facilitated the understanding of the ascomycin biosynthesis network. Using this model in conjunction with the FBA and MOMA algorithms, we identified 29 potential gene overexpression targets according to a ranking of their respective $f_{\mathrm{PH}}$ values. Among all the predicted targets, several targets with high $f_{\mathrm{PH}}$ values (ACACT1r, HACD1, ECOAH1 and CCCR) were found in the ethylmalonylCoA pathway, which had also been confirmed to be an limiting pathway for other products synthesis in some Streptomyces species [54]. In fact, we also found that the ascomycin producing strain of S. hygroscopicus var. ascomyceticus FS35 could utilize acetate and ethylmalonic acid as a sole carbon source (data not shown), indicating the presence of the ethylmalonyl-CoA pathway in this strain. However, the ethylmalonyl-CoA pathway was incomplete in the most reported model of Streptomyces species. According to the conservative analysis of primary metabolism, the related metabolic reactions had been supplied into the general metabolic model by adding additional constraints and the missing reactions in the pathway (Additional file 4). Using the updated model, the targets related to the ethylmalonyl-CoA pathway were still predicted to have great relevance for ascomycin biosynthesis (Additional file 4). Therefore, the targets related to the ethylmalonyl-CoA pathway were successfully predicted to have great relevance for ascomycin biosynthesis (Additional file 4).

Among the above four targets (ACACT1r, HACD1, ECOAH1 and CCCR), HACD1 could converts acetoacetyl-CoA to 3-hydroxybutyryl-CoA through 3-hydroxybutyryl-CoA dehydrogenase encoded by hcd. Furthermore, it is worth mentioning that the metabolite 3-hydroxybutyryl-CoA plays important roles in the ethylmalonyl-CoA pathway and poly-hydroxybutyrate
(PHB) biosynthesis (Fig. 6). PHB had been proved to be relevant to ascomycin biosynthesis in S. hygroscopicus var. ascomyceticus [60]. CCCR is another target involved in the ethylmalonyl-CoA pathway, corresponding to Ccr, which converts crotonyl-CoA to ethylmalonyl-CoA. This enzyme has been used to improve the production of several secondary metabolites in Streptomyces species, including monensin [61], tacrolimus [54], and salinomycin [58]. Furthermore, hcd and $c c r$ are present in gene clusters encoding the ethylmalonyl-CoA pathway in all the examined Streptomyces strains (Additional file 3: Table S3). The target genes $h c d$ and $c c r$ were selected as the gene overexpression targets to further experimentally verify the accuracy of the model prediction and to enhance the production of ascomycin.

The two target genes $h c d$ and $c c r$ were overexpressed and co-overexpressed in S. hygroscopicus var. ascomyceticus. The experimental results suggested that all the engineered strains had a higher ascomycin production than control, and the highest ascomycin production could reach to $438.95 \mathrm{mg} / \mathrm{L}$. The genetic manipulation about the target genes further verified the feasibility the strategy about model construction. However, the increase of production titer was different from the predicted improvements. This may be due to some limitations of the constraint-based metabolic network simulation, such as the lack of detailed knowledge on metabolic regulation, as well as thermodynamic and kinetic information. The strategy for metabolic model construction in Streptomyces species will make the construction process of metabolic network easier and make it possible for the strain without genomic information.

In addition, except for S. hygroscopicus var. ascomyceticus, the ethylmalonyl-CoA pathway is also found in many Streptomyces species, and the corresponding enzymes can be found in 30 of the 31 investigated Streptomyces strains (Additional file 3: Table S3). Enhancing the flux in ethylmalonyl-CoA pathway would improve the pools of many common precursor of in polyketide biosynthesis (Fig. 6), including ethylmalonyl-CoA, methylmalonylCoA, propionyl-CoA, crotonyl-CoA, butyryl-CoA, and so on [48]. In addition, the ethylmalonyl-CoA pathway overlaps with several important metabolic pathways, such as the PHB pathway, TCA cycle and serine cycle, and many PKS gene clusters associated with butyrylcontaining metabolites also contain another copy of the $c c r$ gene to supply ethylmalonyl-CoA $[60,62]$. The complicated relationship between the ethylmalonyl-CoA pathway and other metabolic pathways might open new avenues for the improvement of polyketide production and rational pathway design. 


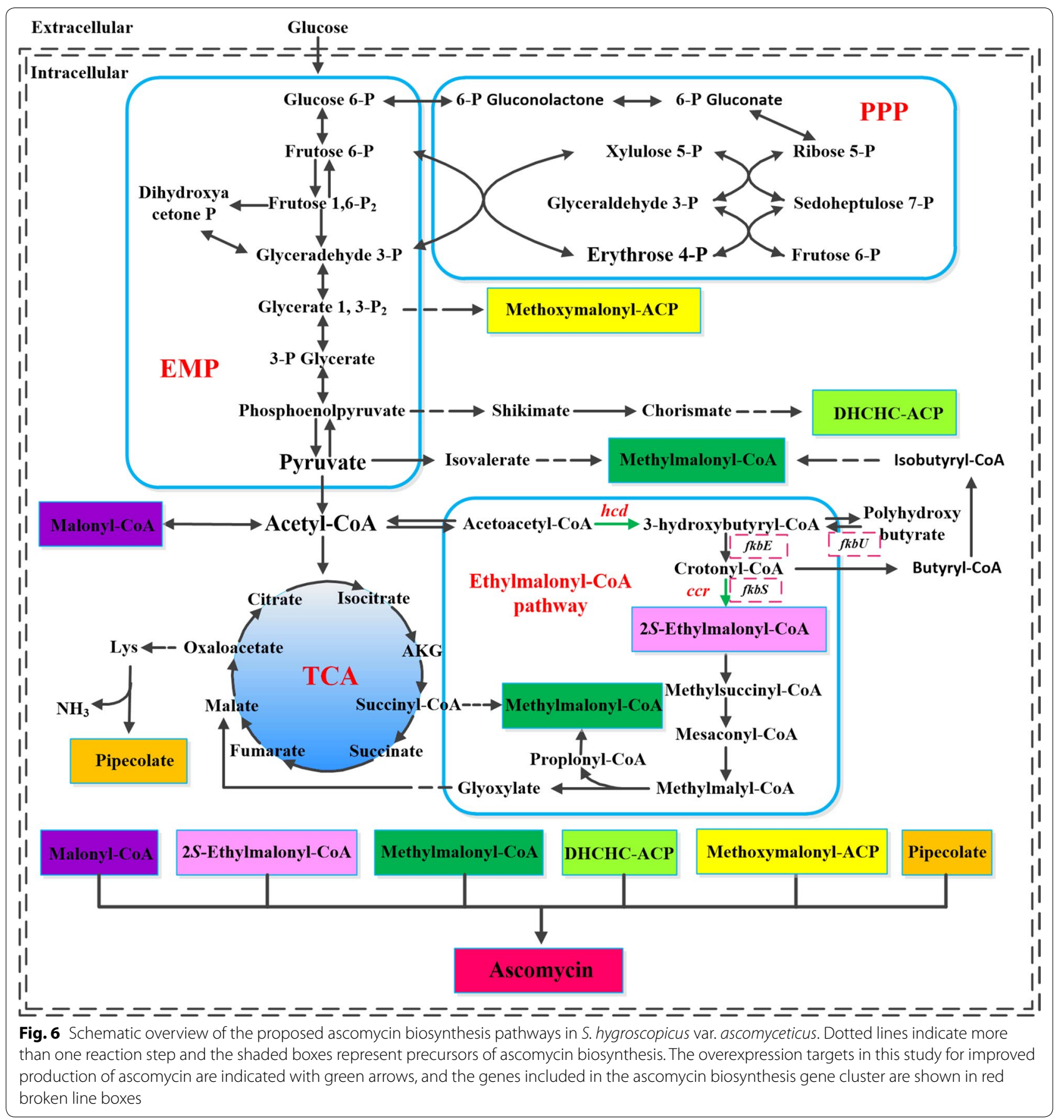

\section{Conclusions}

In this study, using the latest reported model of S. coelicolor A3(2) as model, a general metabolic model of Streptomyces species was attempted to be constructed based on the conservative analysis of the primary metabolic reactions of 31 Streptomyces strains. Using this general metabolic model, the GSMM of S. hygroscopicus var. ascomyceticus was reconstructed and applied to identify the potential targets for ascomycin overproduction. According to the simulated results, two targets hcd and ccr from the ethylmalonyl-CoA pathway were selected for overexpression, the experimental results indicated ascomycin production showed higher improvement in both of single- and double-overexpression strains. These findings could not only indicate that improving the supply of ethylmalonyl-CoA could improve ascomycin yield 
effectively, but also suggest that a general metabolic model could be existed and applied to guide for the yield improvement of other products in Streptomyces species.
Received: 14 June 2017 Accepted: 26 September 2017

Published online: 03 October 2017

\section{Additional files}

Additional file 1. Conservation analysis of the proteins in the model iMK1208 against 31 Streptomyces strains.

Additional file 2. Metabolic network model of S. hygroscopicus var. ascomyceticus FS35 and potential targets identified using this model.

Additional file 3: Table S1. Primers used in this section. Figure S1. Heat map illustrating the conservation of metabolic enzymes in different metabolic subsystems among 31 Streptomyces strains. Figure S2. Homology analysis of proteins related to the primary metabolism of $S$. coelicolor A3(2) and S16-shyl. Figure S3. Production profiles of the stain S. hygroscopicus var. ascomyceticus FS35 in batch fermentation. Table S2. Genetic targets chosen for experimental implementation. Table S3. The encoded enzymes involved in the ethylmalonyl-CoA pathways of the 31 Streptomyces strains.

Additional file 4. The updated model including the complete ethylmalonyl-CoA pathway, and the potential targets identified using this model.

\section{Authors' contributions}

JW carried out the experimental work, analyzed the data and wrote the manuscript. CW performed the partial of metabolic network model reconstruction and experimental analysis, helped in editing and revising the manuscript. KS helped in analyzing the data and writing the manuscript. JPW designed the experiments and supervised the work. All authors read and approved the final manuscript.

\section{Author details}

${ }^{1}$ Key Laboratory of System Bioengineering (Tianjin University), Ministry of Education, Tianjin 300072, People's Republic of China. ${ }^{2}$ SynBio Research Platform, Collaborative Innovation Center of Chemical Science and Engineering (Tianjin), School of Chemical Engineering and Technology, Tianjin University, Tianjin 300072, People's Republic of China.

\section{Acknowledgements}

We want to thank Dr. Huanhuan Liu and Jiao Liu for the comments on our manuscript.

\section{Competing interests}

The authors declare that they have no competing interests.

\section{Availability of data and supporting materials}

All data generated or analyzed during this study are included in this manuscript and in its additional files 1,2,3 and 4.

\section{Consent for publication}

All authors consent to publish this manuscript.

\section{Ethics approval and consent to participate}

This manuscript does not involve the data collected from animals or humans.

\section{Funding}

This work was supported by the National 973 Project of China (No. 2013CB733600), the National Natural Science Foundation of China (No. 21676189), the Key Technologies R\&D Program of Tianjin (No. 16YFZCSY00780) and the Key Program of National Natural Science Foundation of China (No. 21236005).

\section{Publisher's Note}

Springer Nature remains neutral with regard to jurisdictional claims in published maps and institutional affiliations.

\section{References}

1. Arai T, Kouama Y, Suenaga T, Honda H. Ascomycin, an antifungal antibiotic. J Antibiot. 1962;15:231-2.

2. Dumont FJ, Staruch MJ, Koprak SL, Siekierka JJ, Lin CS, Harrison R, et al. The immunosuppressive and toxic effects of FK-506 are mechanistically related: pharmacology of a novel antagonist of FK-506 and rapamycin. J Exp Med. 1992;176:751-60.

3. Monaghan P, Fardis M, Revill WP, Bell A. Antimalarial effects of macrolactones related to FK520 (Ascomycin) are independent of the immunosuppressive properties of the cmpounds. J Infect Dis. 2005;191:1342-9.

4. Jacobi A, Braeutigam M, Mahler V, Schultz E, Hertl M. Pimecrolimus 1\% cream in the treatment of facial psoriasis: a 16-week open-label study. Dermatology. 2008;216:133-6.

5. Sierra-Paredes G, Sierra-Marcuno G. Ascomycin and FK506: pharmacology and therapeutic potential as anticonvulsants and neuroprotectants. CNS Neurosci Ther. 2008;14:36-46.

6. Boone B, Ongenae K, Van Geel N, Vernijns S, De Keyser S, Naeyaert $J M$. Topical pimecrolimus in the treatment of vitiligo. Eur J Dermatol. 2007;17:55-61.

7. Qi H, Xin X, Li S, Wen J, Chen Y, Jia X. Higher-level production of ascomycin (FK520) by Streptomyces hygroscopicus var. ascomyceticus irradiated by femtosecond laser. Biotechnol Bioprocess E. 2012;17:770-9.

8. Parveen K, Kumar S, Kumar M. An improved fermentation process for preparing ascomycin. Patent WO 2007/29082 A2. 2007.

9. Qi H, Zhao S, Fu H, Wen J, Jia X. Enhancement of ascomycin production in Streptomyces hygroscopicus var. ascomyceticus by combining resin HP20 addition and metabolic profiling analysis. J Ind Microbiol Biotechnol. 2014:41:1365-74.

10. Thiele I, Palsson BO. A protocol for generating a high-quality genomescale metabolic reconstruction. Nat Protoc. 2010;5:93-121.

11. Lee KY, Park JM, Kim TY, Yun H, Lee SY. The genome-scale metabolic network analysis of Zymomonas mobilis ZM4 explains physiological features and suggests ethanol and succinic acid production strategies. Microb Cell Fact. 2010;9:94.

12. Wang X, Zhang C, Wang M, Lu W. Genome-scale metabolic network reconstruction of Saccharopolyspora spinosa for spinosad production improvement. Microb Cell Fact. 2014;13:41.

13. Huang D, Li S, Xia M, Wen J, Jia X. Genome-scale metabolic network guided engineering of Streptomyces tsukubaensis for FK506 production improvement. Microb Cell Fact. 2013;12:52.

14. Hao T, Han BB, Ma HW, Fu J, Wang H, Wang ZW, et al. In silico metabolic engineering of Bacillus subtilis for improved production of riboflavin, Egl237, $(R, R)-2,3-$ butanediol and isobutanol. Mol BioSyst. 2013;9:2034-44.

15. Mishra P, Park GY, Lakshmanan M, Lee HS, Lee H, Chang MW, et al. Genome-scale metabolic modeling and in silico analysis of lipid accumulating yeast Candida tropicalis for dicarboxylic acid production. Biotechnol Bioeng. 2016;113:1993-2004.

16. Park JM, Park HM, Kim WJ, Kim HU, Kim TY, Lee SY. Flux variability scanning based on enforced objective flux for identifying gene amplification targets. BMC Syst Biol. 2012;6:106.

17. Bentley SD, Chater KF, Cerdeno-Tarraga AM, Challis GL, Thomson NR, James KD, et al. Complete genome sequence of the model actinomycete Streptomyces coelicolor A3(2). Nature. 2002;417:141-7.

18. Borodina I, Krabben P, Nielsen J. Genome-scale analysis of Streptomyces coelicolor A3(2) metabolism. Genome Res. 2005;15:820-9.

19. Alam MT, Merlo ME, Hodgson DA, Wellington EM, Takano E, Breitling R. Metabolic modeling and analysis of the metabolic switch in Streptomyces coelicolor. BMC Genom. 2010;11:202

20. Kim M, Sang Yi J, Kim J, Kim JN, Kim MW, Kim BG. Reconstruction of a high-quality metabolic model enables the identification of gene overexpression targets for enhanced antibiotic production in Streptomyces coelicolor A3 (2). Biotech J. 2014;9:1185-94.

21. Vieira G, Sabarly V, Bourguignon P-Y, Durot M, Le Fèvre F, Mornico D, et al. Core and panmetabolism in Escherichia coli. J Bacteriol. 2011;193:1461-72. 
22. Baumler DJ, Peplinski RG, Reed JL, Glasner JD, Perna NT. The evolution of metabolic networks of E. coli. BMC Syst Biol. 2011;5:182.

23. Nett M, Ikeda H, Moore BS. Genomic basis for natural product biosynthetic diversity in the actinomycetes. Nat Prod Rep. 2009;26:1362-84.

24. Kim JN, Kim Y, Jeong Y, Roe JH, Kim BG, Cho BK. Comparative genomics reveals the core and accessory genomes of Streptomyces species. J Microbiol Biotechnol. 2015;25:1599-605.

25. Kauffman KJ, Prakash P, Edwards JS. Advances in flux balance analysis. Curr Opin Biotech. 2003;14:491-6.

26. Segre D, Vitkup D, Church GM. Analysis of optimality in natural and perturbed metabolic networks. Proc Natl Acad Sci USA. 2002;99:15112-7.

27. Coze F, Gilard F, Tcherkez G, Virolle M-J, Guyonvarch A. Carbon-flux distribution within Streptomyces coelicolor metabolism: a comparison between the actinorhodin-producing strain M145 and Its non-producing derivative M1146. PLOS ONE. 2013;8:e84151.

28. van Wezel GP, Konig M, Mahr K, Nothaft H, Thomae AW, Bibb M, et al. A new piece of an old jigsaw: glucose kinase is activated posttranslationally in a glucose transport-dependent manner in Streptomyces coelicolor A3(2). J Mol Microbiol Biotechnol. 2007;12:67-74.

29. Qi H, Lv M, Song K, Wen J. Integration of parallel 13C-labeling experiments and in silico pathway analysis for enhanced production of ascomycin. Biotechnol Bioeng. 2017;114:1036-44.

30. Avignone Rossa C, White J, Kuiper A, Postma PW, Bibb M, Teixeira de Mattos MJ. Carbon flux distribution in antibiotic-producing chemostat cultures of Streptomyces lividans. Metab Eng. 2002;4:138-50.

31. Schellenberger J, Que R, Fleming RMT, Thiele I, Orth JD, Feist AM, et al. Quantitative prediction of cellular metabolism with constraint-based models: the COBRA Toolbox v2.0. Nat Protoc. 2011;6:1290-307.

32. Gilat A. MATLAB: an introduction with applications. New York: Wiley; 2009.

33. Valipour M, Sefidkouhi MAG, Raeini M. Selecting the best model to estimate potential evapotranspiration with respect to climate change and magnitudes of extreme events. Agric Water Manag. 2017;180:50-60.

34. Valipour M, Montazar AA. An evaluation of SWDC and WinSRFR models to optimize of infiltration parameters in furrow irrigation. Am J Sci Res. 2012;69:128-42

35. Valipour M. Increasing irrigation efficiency by management strategies: cutback and surge irrigation. ARPN J Agric Biol Sci. 2013;8:35-43.

36. Heavner BD, Smallbone K, Barker B, Mendes P, Walker LP. Yeast 5-an expanded reconstruction of the Saccharomyces cerevisiae metabolic network. BMC Syst Biol. 2012;6:55.

37. Boghigian BA, Armando J, Salas D, Pfeifer BA. Computational identification of gene over-expression targets for metabolic engineering of taxadiene production. Appl Microbiol Biotechnol. 2012;93:2063-73.

38. Qi H, Zhao S, Wen J, Chen Y, Jia X. Analysis of ascomycin production enhanced by shikimic acid resistance and addition in Streptomyces hygroscopicus var. ascomyceticus. Biochem Eng J. 2014;82:124-33.

39. Kieser T. Practical Streptomyces genetics. London: John Innes Foundation; 2000.

40. MacNeil DJ, Gewain KM, Ruby CL, Dezeny G, Gibbons PH, MacNeil T. Analysis of Streptomyces avermitilis genes required for avermectin biosynthesis utilizing a novel integration vector. Gene. 1992;111:61-8.

41. Martinez E, Bartolomé B, de la Cruz F. pACYC184-derived cloning vectors containing the multiple cloning site and lacZa reporter gene of pUC8/9 and pUC18/19 plasmids. Gene. 1988;68:159-62.

42. Wilkinson CJ, Hughes-Thomas ZA, Martin CJ, Bohm I, Mironenko T, Deacon $M$, et al. Increasing the efficiency of heterologous promoters in actinomycetes. J Mol Microbiol Biotechnol. 2002;4:417-26.

43. Bierman M, Logan R, O'Brien K, Seno ET, Rao RN, Schoner BE. Plasmid cloning vectors for the conjugal transfer of DNA from Escherichia coli to Streptomyces spp. Gene. 1992;116:43-9.

44. Wang B, Liu J, Liu H, Huang D, Wen J. Comparative metabolic profiling reveals the key role of amino acids metabolism in the rapamycin overproduction by Streptomyces hygroscopicus. J Ind Microbiol Biotechnol. 2015:42:949-63.
45. Bradford MM. A rapid and sensitive method for the quantitation of microgram quantities of protein utilizing the principle of protein-dye binding. Anal Biochem. 1976;72:248-54.

46. Youngleson JS, Jones DT, Woods DR. Homology between hydroxybutyryl and hydroxyacyl coenzyme A dehydrogenase enzymes from Clostridium acetobutylicum fermentation and vertebrate fatty acid beta-oxidation pathways. J Bacteriol. 1989;171:6800-7.

47. Bond-Watts BB, Bellerose RJ, Chang MC. Enzyme mechanism as a kinetic control element for designing synthetic biofuel pathways. Nat Chem Biol. $2011 ; 7: 222-7$

48. Erb TJ, Berg IA, Brecht V, Müller M, Fuchs G, Alber BE. Synthesis of C5-dicarboxylic acids from C2-units involving crotonyl-CoA carboxylase/ reductase: the ethylmalonyl-CoA pathway. Proc Natl Acad Sci USA. 2007;104:10631-6.

49. DuBois M, Gilles KA, Hamilton JK, Rebers P, Smith F. Colorimetric method for determination of sugars and related substances. Anal Chem. 1956;28:350-6.

50. Erb TJ, Rétey J, Fuchs G, Alber BE. Ethylmalonyl-CoA mutase from Rhodobacter sphaeroides defines a new subclade of coenzyme B12-dependent acyl-CoA mutases. J Biol Chem. 2008;283:32283-93.

51. Kupke T, Hernandez-Acosta P, Steinbacher S, Culianez-Macia FA. Arabidopsis thaliana flavoprotein AtHAL3a catalyzes the decarboxylation of 4'-phosphopantothenoylcysteine to 4'-phosphopantetheine, a key step in coenzyme A biosynthesis. J Biol Chem. 2001;276:19190-6.

52. Johnson MNR, Londergan CH, Charkoudian LK. Probing the phosphopantetheine arm conformations of acyl carrier proteins using vibrational spectroscopy. J Am Chem Soc. 2014;136:11240-3.

53. Volk K, Breunig SD, Rid R, Herzog J, Braeuer M, Hundsberger $\mathrm{H}$, et al. Structural analysis and interaction studies of acyl-carrier protein (acpP) of Staphylococcus aureus, an extraordinarily thermally stable protein. Biol Chem. 2017:398:125-33.

54. Jung WS, Kim E, Yoo YJ, Ban YH, Kim EJ, Yoon YJ. Characterization and engineering of the ethylmalonyl-CoA pathway towards the improved heterologous production of polyketides in Streptomyces venezuelae. Appl Microbiol Biotechnol. 2014;98:3701-13.

55. Mo S, Ban Y-H, Park JW, Yoo YJ, Yoon YJ. Enhanced FK506 production in Streptomyces clavuligerus CKD1119 by engineering the supply of methylmalonyl-CoA precursor. J Ind Microbiol Biotechnol. 2009;36:1473-82.

56. Huang D, Xia M, Li S, Wen J, Jia X. Enhancement of FK506 production by engineering secondary pathways of Streptomyces tsukubaensis and exogenous feeding strategies. J Ind Microbiol Biotechnol. 2013;40:1023-37.

57. Chen D, Zhang Q, Zhang Q, Cen P, Xu Z, Liu W. Improvement of FK506 production in Streptomyces tsukubaensis by genetic enhancement of the supply of unusual polyketide extender units via utilization of two distinct site-specific recombination systems. Appl Environ Microbiol. 2012;78:5093-103.

58. Lu C, Zhang X, Jiang M, Bai L. Enhanced salinomycin production by adjusting the supply of polyketide extender units in Streptomyces albus. Metab Eng. 2016;35:129-37.

59. D'Huys P-J, Lule I, Vercammen D, Anne J, Van Impe JF, Bernaerts K. Genome-scale metabolic flux analysis of Streptomyces lividans growing on a complex medium. J Biotechnol. 2012;161:1-13.

60. Wu K, Chung L, Revill WP, Katz L, Reeves CD. The FK520 gene cluster of Streptomyces hygroscopicus var. ascomyceticus (ATCC 14891) contains genes for biosynthesis of unusual polyketide extender units. Gene. 2000;251:81-90.

61. Li CX, Florova G, Akopiants K, Reynolds KA. Crotonyl-coenzyme A reductase provides methylmalonyl-CoA precursors for monensin biosynthesis by Streptomyces cinnamonensis in an oil-based extended fermentation. Microbiology. 2004;150:3463-72.

62. Wilson MC, Moore BS. Beyond ethylmalonyl-CoA: the functional role of crotonyl-CoA carboxylase/reductase homologs in expanding polyketide diversity. Nat Prod Rep. 2012;29:72-86. 